\section{International Scientific Journal} Theoretical \& Applied Science

p-ISSN: 2308-4944 (print) e-ISSN: 2409-0085 (online)

Year: 2017 Issue: 03 Volume: 47

Published: $30.03 .2017 \quad$ http://T-Science.org
Svetlana Anatol'evna Balyaeva Professor, Doktor of Pedagogical Science,

Professor Department of Physics, State Maritime University Admiral Ushakov, Russia sergei_mishik@mail.ru

SECTION 21. Pedagogy. Psychology. Innovation in Education.

\title{
PEDAGOGICAL INNOVATIONS IN THE CONTEXT OF FORMING THE PROFESSIONAL COMPETENCE OF ENGINEERING SPECIALISTS OF THE MARINE BRANCH
}

Abstract: Pedagogical innovations in the context of forming the professional competencies of specialists of the navy. Special attention is paid to innovative didactic technologies as a way to increase the efficiency of general scientific training at the Maritime University.

Key words: pedagogical innovations, professional competence, system of higher marine education.

Language: Russian

Citation: Balyaeva SA (2017) PEDAGOGICAL INNOVATIONS IN THE CONTEXT OF FORMING THE PROFESSIONAL COMPETENCE OF ENGINEERING SPECIALISTS OF THE MARINE BRANCH. ISJ Theoretical \& Applied Science, 03 (47): 139-142.

Soi: http://s-o-i.org/1.1/TAS-03-47-24 Doi: crossef https://dx.doi.org/10.15863/TAS.2017.03.47.24

УДК 372.851

\section{ПЕДАГОГИЧЕСКИЕ ИННОВАЦИИ В КОНТЕКСТЕ ФОРМИРОВАНИЯ ПРОФЕССИОНАЛЬНОЙ КОМПЕТЕНТНОСТИ ИНЖЕНЕРНЫХ СПЕЦИАЛИСТОВ МОРСКОЙ ОТРАСЛИ}

Аннотация: Рассмотрены педагогические инновации в контексте формирования профессиональных компетенциий спецциалистов морского флота. Особое внимание уделено инновационным дидактическим технологиям как способу повышения эффективности общенаучной подготовки в морском университете.

Ключевые слова: педагогические инновации, профессиональная компетентность, система высшего морского образования

\section{Introduction}

Одной из важных задач реформирования российской системы высшего образования в целом и инженерно-морского, в частности, осуществляемое в настоящее время в нашей стране, является разработка и внедрение инновационных технологий обучения в учебный процесс высшей школы с целью повышения качества подготовки будущих специалистов.

Инновационный педагогический потенциал России достаточно велик и определяется следующими факторами: наличием развитой системы университетского и высшего педагогического образования;существованием по некоторым направлениям психологопедагогических исследований признанных научных школ мирового уровня; наличием значительного количества квалифицированных кадров, занятых в системе образования; настоятельной и все возрастающей потребностью в технологическом обновлении учебного процесса[1].

\section{Materials and Methods}

Однако указанные факторы не реализуются автоматически. На пути их превращения в источники инновационного роста в сфере инженерно-морского образования встает целый ряд проблем, требующих актуального решения. Дело в том, что инновационная составляющая в этой сфере технического образования проявляет себя недостаточно активно. Поэтому без выявления причин, препятствующих широкой реализации инновационного педагогического потенциала в высших морских учебных заведениях, нельзя предложить эффективную 
инновационную модель подготовки специалистов морской отрасли.

В российской системе высшего технического образования как в целом, так и инженерно- морского в частности, в настоящее время наблюдается, на наш взгляд, отсутствие достаточно масштабных перспектив реализации инновационного педагогического потенциала и создания инновационных моделей обучения, основанных на рыночных требованиях к подготовке современных инженерных кадров. Распад плановой экономики привел к нарушениям в работе отдельных звеньев образовательной сферы, для устранения которых и придания целостного характера системы образования необходимо:

- повысить эффективность подготовки педагогических кадров для инновационной деятельности в сфере образования;

- создать центры национальной координации инновационной педагогической деятельности;

- организовать масштабные исследования;$$
\text { - }
$$$$
\text { расширить систему }
$$

финансировать и
научно-педагогические педагогической информации;

- развернуть масштабную реализацию педагогических инноваций в высших учебных заведениях.

Заметим, что реализация педагогических новшеств в учебных заведениях воздействует одновременно на различные структуры педагогической системы, такие как подготовку педагогических кадров, организацию научных исследований, внедрение инновационных технологических разработок и др. Необходимо также учитывать, что сфера создания педагогических новшеств является частично автономной, а частично испытывает воздействие новых общественных потребностей, формирующихся в ходе потребления результатов предыдущих инноваций. При этом каждая связка в сложной цепочке взаимодействий конкретных структур педагогической системы требует выработки специфических педагогических механизмов и методов управления педагогическими инновациями [2,3].

Реформирование системы высшего образования, происходящее в нашей стране, разумеется, предполагает реформирование и школьного образования. В современных условиях высшая школа ощущает, что качество традиционно сложившегося школьного образования из-за низкого уровня финансирования постепенно ухудшается. Не найдены пока формы и методы ориентации школьного образования на потребности общественного развития. Реформа высшего образования, как и средней школы, требует модернизации технологий и программ обучения, что тесно связано с осуществлением педагогических инновационных процессов в образовательной сфере. Однако решение этой проблемы невозможно без широкой мобилизации социальных стимулов и превращения обучения и воспитания в творческий процесс $[4,5]$.

Применительно к системе высшего инженерно-морского образования наиболее актуальными инновациями, на наш взгляд, являются технологии обучения, направленные, прежде всего, на переориентацию целей высшего морского образования на опережающую подготовку специалистов и профессионалов, обладающих оптимальным набором инженерно-морских компетенций, позволяющим выпускникам морского университета быть конкурентоспособными на рынке труда, готовыми к осуществлению инновационной инженерной деятельности при переходе из одной морской производственной сферы в другую.

Профессиональная компетентность инженерных специалистов морской отрасли имеет сложную структуру, в которой целесообразно, на наш взгляд, выделить инвариантную и вариативную оболочки. Каждая из этих оболочек может включать соответствующий ряд уровней. Так, в качестве ядра инвариантной оболочки мы рассматриваем базовый, инженерно-технологический, специально-морской уровни, а так же интегративно-контекстный уровень иноязычной подготовки морских инженеров. В составе вариативной оболочки можно выделить общекультурный, социально-правовой и личностно-креативный уровни.

Bсе обозначенные выше уровни содержат адекватный профилю формируемого специалиста набор компетенций, включающий предметноспецифические, общекультурные и профессиональные составляющие. В процессе общенаучной подготовки специалистов морского флота формируются компетенции базового уровня. В морском университете математические, естественнонаучные и другие дисциплины цикла общенаучной подготовки обеспечивают инструментарий формирования совокупности ведущих предметно-специфических, общекультурных и профессиональных компетенций специалистов инженерно-морского профиля [6].

Особо отметим, что организация общенаучной подготовки в системе высшего морского образования на базе инновационных компьютерных и дидактических технологий требует пересмотра не только содержания и структуры, но и способов усвоения общенаучных дисциплинарных курсов, которые наряду с 
системой предметно-специфических знаний должны формировать адекватные виды учебной квазипрофессиональной деятельности, включающие механизмы саморазвития и личностного профессионального роста будущих специалистов морского флота [7].

Реализация педагогических инноваций на этапе общенаучной подготовки в морском университете открывает возможности преобразования традиционного обучения по общенаучным дисциплинам из недостаточно эффективного и устаревшего по своей организации и методике в высокоэффективный профессионально ориентированный учебный процесс, соответствующий новым образовательным стандартам последнего поколения $[8,9,10]$. Развитие базы данных педагогометрических моделейформирующего эрцгаммного анализа образовательных объектовпри формированииматематических моделей учебной деятельности относительно способа достижения критериев эрцгаммности на различных целостно-системных представлениях о профессиональной практической деятельности связывается с различными информационными представлениями об ориентировочных, исполнительных и контрольных качествах технологических процессов [10].

\section{Conclusion}

Комплексный подход к организации этапов обучения по циклу общенаучных дисциплин, включающий в качестве основных составляющих системно-деятельностный, компетентностный, личностно-ориентированный и интерактивный подходы, может выступать основным ориентиром перестройки учебно-воспитательного процесса, гарантирующим создание действительно современной системы обучения, отвечающей вызовам современного рынка труда и обеспечивающей достаточно высокие результаты общенаучной подготовки в морском университете.

\section{References:}

1. Balyaeva SA, Khvingiya TG (2013) Innovacionnyy pedagogicheskiy potencial i ego realizaciya $\mathrm{v}$ sfere inzhenerno-morskogo obrazovaniya// Izvestiya Yuzhnogo federalnogo universiteta. Pedagogicheskie nauki. 2013. №3. p.21-27.

2. Balyaeva SA, Uglova AN (2014) Teoreticheskie osnovy pedagogicheskikh innovaciy// Ekspluataciya, bezopasnost i ekonomika vodnogo transporta. Vestnik GMU im. adm. F.F. Ushakova.- Novorossiysk: izd-vo GMU im. adm. F.F. Ushakova. 2014. №2 (7). p. 79-82.

3. Balyaeva SS, Uglova AN (2014) Innovacionnye didakticheskie tekhnologii kak sredstvo formirovaniya universalnykh professionalnykh kompetenciy inzhenerov morskogo flota / V kn.: Obrazovatelno-innovacionnye tekhnologii: teoriya i praktika: monografiya; pod obshchey red. Prof. O.I. Kirikova.-Kniga 19.- Moskva: Nauka: inform; Voronezh: VGPU. 2014. p.121-136.

4. Mishchik SA (2016) Pedagogometricheskoe modelirovanie obrazovatelnoy deyatelnosti//Uspekhi sovremennoy nauki i obrazovaniya. - 2016, №8, Tom 1 - Belgorod, p.85-87.
5. Mishchik SA (2016) Erczgammnost - bazisnyy princip podgotovki shirokoprofilnykh specialistov/Obrazovatelno-innovacionnye tekhnologii: teoriya i praktika [Tekst]: monografiya / [K.I.Alieva,D.O.Alimova, V.V.Arkhipov i dr.]; pod obshchey red. prof. O.I.Kirikova - Kniga 26.- Voronezh: VGPU; Moskva: Nauka: inform, 2016. - 198 p. (25-36 p.) ISBN978-5-00044-416-0

6. Tokmazov GV, Pankina SI (2009) Strukturnosoderzhatelnaya model formirovaniya issledovatelskikh umeniy // Vysshee obrazovanie segodnya. 2009. № 1. p. 63-66.

7. Balyaeva SA (1999) Teoreticheskie osnovy fundamentalizacii obshchenauchnoy podgotovki v sisteme vysshego tekhnicheskogo obrazovaniya.Avtoref. diss. dokt. ped. nauk Moskva: Izd-vo MPGU, 1999.- 32 p.

8. Balyaeva SA (2016) Information modelasameans of for mationof professional integrity of knowledge of maritime transport [Tekst] /S.A.Balyaeva // Materialy Mezhdunarodnoy nauchnoy konferenctsii «Global Science» - $30.04 .2016 \quad$ ISJ Theoretical \& Applied Science, 04 (36): 141143. Lancaster, USA. http://dx.doi.org/10.15863/TAS.2016.04.36.23 


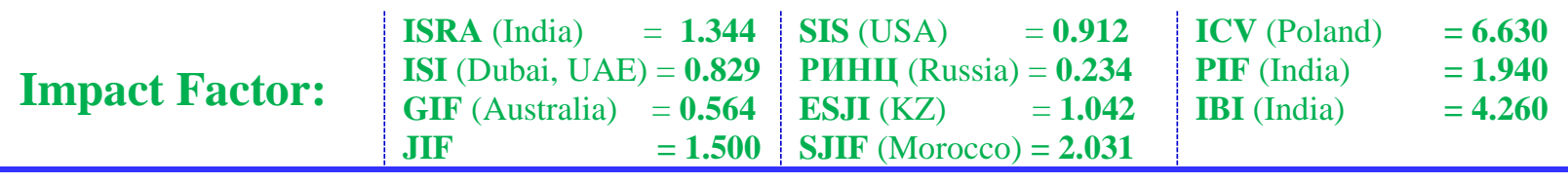

9. Balyaeva SA, Uglova AN (2012) Povyshenie effektivnosti obshchenauchnoy podgotovki specialistov morskoy otrasli na baze innovacionnykh didakticheskikh tekhnologiy // Nauchnye problemy gumanitarnykh issledovaniy. 2012. №5. p. 95-106.
10. Balyaeva SA, Uglova AN (2016) Tekhnologicheskie podkhody k proektirovaniyu soderzhaniya kursa fiziki v morskom vuze // Obshchestvo: sociologiya, psikhologiya, pedagogika. 2016. №5. p.93-96. 